\title{
PReS-FINAL-2191: Imaging of chronic recurrent multifocal osteitis: a french national cohort of 178 cases
}

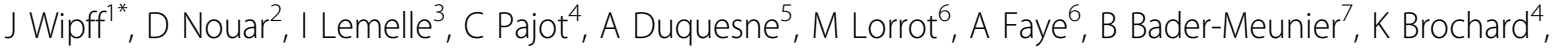

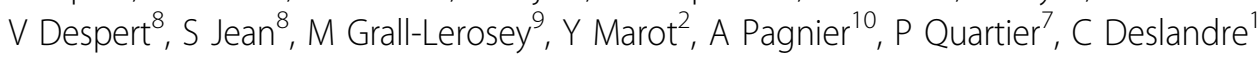 \\ From 20th Pediatric Rheumatology European Society (PReS) Congress \\ Ljubljana, Slovenia. 25-29 September 2013
}

\section{Introduction}

The radiological assessment of CRMO is currently the subject of discussions and the recent use of whole-body MRI leads to discuss the respective roles of the imaging techniques.

\section{Objectives}

This study provides a descriptive evaluation of imaging OCMR, its diagnostic management and a comparison between different techniques.

\section{Methods}

178 CRMO patients were included (123 females and 55 males). The lesions detected by imaging (plain radiographs, isotopic bone scan and/or MRI) were collected by specifying the number, location (bone, proximal/distal and metaphyseal/epiphyseal/diaphyseal), character (lytic/sclerotic/mixed) and the signal MRI T1 and T2.

\section{Results}

The average number of lesions per patient detected before diagnosis was $3.5 \pm 2.9$ [1-26]. The mean number of lesions was $1 \pm 0.9$ by radiographs, $2.45 \pm 1.7$ by isotopic bone scan and $3.12 \pm 1.33$ by MRI.

A total of 193 radiographic lesions were detected with the following distribution: tibia $(\mathrm{n}=44)$, the clavicle $(\mathrm{n}=34)$, the femur $(\mathrm{n}=23)$, the fibula $(\mathrm{n}=20)$ and pelvis $(n=19)$. The lesions of the lower limbs accounted for $52 \%$ of the lesions. The lesions of the long bones were most often located in metaphyseal $(58 / 76,76 \%)$

1Rheumatology A, Inserm U1016, University Paris Descartes, Aphp, Paris, France

Full list of author information is available at the end of the article and were lytic in $76 / 162(47 \%)$ and sclerotic in $60 /$ 162 (37\%).

The isotopic bone scan detected 372 lesions localized to the pelvis $(n=64)$, tibia $(n=51)$, femur $(n=44)$, clavicle $(n=40)$ and vertebrae $(n=29)$. The lesions were mainly metaphyseal $(65 / 92,56 \%)$.

MRI detected 515 lesions distributed as follows: pelvis $(\mathrm{n}=100)$, tibia $(\mathrm{n}=93)$ and femur $(\mathrm{n}=73)$ are the sites most frequently affected. 51 vertebral lesions $(10 \%)$ were detected in 36 patients. Most of them were localized at the thoracic level. The vast majority of lesions were hypo-T1 and hyper-T2. The description of bone lesions with MRI seems to be more accurate (metaphysoepiphyseal) and more frequently bilateral and symmetric.

Imaging has allowed confirming the multifocal pattern in 26/54 patients with clinical monofocal at diagnosis. Of the remaining 28 patients with monofocal lesion, the clinical course and imaging confirmed the multifocal pattern in 16 additional cases: a total of only 12 patients (7\%) kept a pure monofocal evolution.

In 15 patients, scintigraphy and whole-body MRI were performed at the same time (+/- 3 months). Analysis of these 15 patients showed a higher sensitivity to detect lesions by MRI $(6.7 \pm 3.1$ vs $3.4 \pm 2.4, p=0.003)$ and better description of lesions.

Jansson score that integrates imaging, was interpretable in 110 patients: the application of this score would have, in this cohort, to avoid 27/110 biopsies.

\section{Conclusion}

The study of imaging in this large CRMO French cohort confirms the interest of imaging to characterize multifocal involvement of CRMO and to prevent invasive diagnostic procedures. MRI confirms its sensitivity to detect 
more lesions including spinal and pelvis than isotopic bone scan. MRI provided a more detailed description of the osteitis lesions.

\section{Disclosure of interest}

None declared.

\section{Authors' details}

'Rheumatology A, Inserm U1016, University Paris Descartes, Aphp, Paris, France. ${ }^{2}$ Paediatric, Hospital, Tours, France. ${ }^{3}$ Paediatric, Hospital CHU, Nancy, France. ${ }^{4}$ Paediatric, Hospital, Toulouse, France, France. ${ }^{5}$ Paediatric, Hospital, Lyon, France. ${ }^{6}$ Paediatric, Hospital CHU R Debré, France. ${ }^{7}$ Paediatric, $\mathrm{CHU}$ Necker, Paris, France. ${ }^{8}$ Paediatric, Hospital CHU, Rennes, France. ${ }^{9}$ Paediatric, Hospital, Rouen, France. ${ }^{10}$ Paediatric, Hospital, Grenoble, France.

Published: 5 December 2013

Submit your next manuscript to BioMed Central and take full advantage of:

- Convenient online submission

- Thorough peer review

- No space constraints or color figure charges

- Immediate publication on acceptance

- Inclusion in PubMed, CAS, Scopus and Google Scholar

- Research which is freely available for redistribution

Submit your manuscript at www.biomedcentral.com/submit 